\title{
EXPLORATORY ANALYSIS OF PILOT DATA: TRENDS OF GADGET USE AND PSYCHOSOCIAL ADJUSTMENT IN PRE-SCHOOLERS
}

\author{
Khiu, Alexander L. ${ }^{1} \&$ Hazalizah Hamzah ${ }^{2}$ \\ Faculty of Human Development, Sultan Idris Education University, \\ Tanjong Malim,Perak,Malaysia \\ alexkhiuhuat@gmail.com¹, hazalizah@fpm.upsi.edu.my ${ }^{2}$
}

\begin{abstract}
Current mobile media presence in the lives of young children are at an all-time high prompting the need for studies to examine this phenomenon. The current study aims to describe the trends of gadget use and to explore the relationship between gadget use duration and psychosocial adjustment variables among Malaysian pre-schoolers. The respondents of the current study were 27 parents of pre-schoolers and a majority of the sample were Malays (96.3\%). Mean age of parents in this study for mothers $(\mathrm{M}=35.58, \mathrm{SD}=4.45)$ and fathers $(\mathrm{M}=36.42, \mathrm{SD}=4.58)$. This study employed the gadget use survey and the Malay version of the Strength and Difficulties Questionnaire (SDQ). It was found that the most commonly available and used device was smartphones and that children mainly used mobile devices for leisure purposes such as watching videos and playing games. An alarming number of children, more than $40 \%$, did not adhere to AAP recommendation of less than 2 hours of media usage daily. A key finding was that the functional relationship between psychosocial adjustment variables and duration of use is curvilinear in nature. However, with a small sample size, caution must be applied, as the findings might not be transferrable to the population.
\end{abstract}

Keywords: trends, media use, gadget and psychosocial adjustment

\section{INTRODUCTION}

The first two decades of the 21st Century saw the inevitable rise of the Information and Technology era resulting in a phenomenon known as growing up digital among children. Today children are growing up as digital natives and as a result we are experiencing unprecedented levels of media use among young children. In a study of mobile device (smartphone and tablets) use among children it was shown that $96.6 \%$ of the sample had used mobile devices with most of them starting before the age of 1 and at age 2 most of these children were using these devices on a daily basis (Kabali et al., 2015). Additionally, the media industry has begun to shift their focus customer base to include children, evident in Apples app store having more than 80,000 applications labelled educational meant for children (Apple, September 29, 2017). Similarly, for Android users the Google Play Store boasts an equally large array of educational applications, the most common individual category accounting for $8 \%$ of the one million applications available (Pew Research Centre, November 10, 2015).

The trend is equally alarming in Malaysia, in the first quarter of 2017 the Malaysian Communications and Multimedia Commission (MCMC) reported that the national broad- band penetration rate was $81.8 \%$, an all-time high. Yet another worrisome figure is the mobile device or smartphone penetration rate of 134 devices per 100 inhabitants (MCMC, September 29, 2017). This would mean that there is more than one smartphone for each Malaysian. It is 
arguable that a child may not own a smartphone but the increasing presence of smartphones in a childs life and that application developers have begun to divert their attention towards children as consumers is a cause for concern. It appears that mobile devices are a part of childrens lives today and it would be impractical and almost impossible to prevent their exposure to mobile devices. The challenge at hand is managing the media consumption among children and some parties have resorted to relatively extreme means such as punishing parents with hefty fines and even, jail time.

The American Academy of Pediatrics (AAP) has long expressed concerns over children's media use through a series of public policy statements urging parents to limit their children's exposure to media (AAP, 2016, 1999, 2011). Similarly, stakeholders in other countries such as Australia and Canada have expressed similar apprehensions toward media use in children suggesting that parents limit usage of electronic devices to no more than 1 hour per day for children aged between two to four while children below two are not allowed to use media (Canadian Society for Exercise Physiology, 15 June, 2017; Australian Department of Health, 15 June, 2017). Some countries have taken drastic measures such as enacting legislature to limit media use in youth. Most notably the Taiwanese Yuan passed a new legislation where parents would be fined, between NT\$ 10,000 to NT\$ 50,000, if their children are using electronic devices for an unreasonable amount of time entitled Protection of Children, Youths Welfare Rights Act Protection of Children \& Youths Welfare \& Rights Act (2017). The legislation limits the use of electronic devices to no more than 30 minutes in a single session and bans children below the age of two from using these devices. In South Korea, law makers have made it compulsory for developers to include preventative measures of game overuse such as placement of warning notice to prevent excessive use of gaming products and also, to indicate the passage of time on screen (Game Industry Promotion Act, 2015).

To best of this authors knowledge little to no such precautionary measures have been taken in Malaysia despite the ubiquity of mobile devices in children's lives. This perhaps could be attributed to the fact that there is very little research conducted on the potential effects of media use in children (Kabali et al., 2015; Radesky et al., 2015). Consequently, this study aims to describe the trends of gadget use in pre-schoolers and to explore the relationship between media usage and psychosocial adjustment variables using data from a small scale pilot study. The exploration of the dataset will enable us to gain a better insight of the characteristics of the data such as underlying structures which we can take into account during when modelling the data.

One of the most common assumptions in quantitative psychology with regards to data is the linearity assumption, whereby the functional relationship between the dependent and independent variables are assumed to be linear. It is necessary here to clarify what it means by the term functional relationship which is the mathematical form of the relationship between variables and it is typically expressed as an equation. While there are countless number of functional relationships, in general they can be classifed into linear, exemplified by the equation $\mathrm{y}=\mathrm{mx}+\mathrm{c}$, and non-linear which encompasses all other equations.

However, in social sciences the latter is more often than not true (Keele, 2008). Often times, assuming that the relationship is linear is an oversimplification of the functional relationship and results in failure to adequately describe the relationship. Keele (2008) suggested that nonparametric regression methods employing smoothing methods such as smoothing splines and localised polynomial regression using locally estimated scatterplot smoothing (loess) or weighted locally estimated scatterplot smooth (lowess) are used with data in social sciences. 
This study employs the loess smoothing method to describe the relationship between psychosocial variables and gadget use duration.

\section{Media Use and Social Issues}

Recent studies on media usage among children have investigated the potential detrimental effects of media use on social factors such as lower school achievement (Fitzpatrick et al., 2012; Johnson, 2012), increased aggression (Conners-Burrow et al., 2011; Gentile et al., 2014) and decreased pro-social behavior (Fitzpatrick et al., 2012; Gentile et al., 2014). While, in general media use appears to have negative consequences, literature has emerged that offers contradictory findings. For example, Johnson (2012) suggested the type of media used may influence the effects. In his study, he discovered that academic achievement is negatively associated with playing video games and watching television while it is positively associated with internet use. In another study, it was found that the amount of time spent watching television or videos was not associated with aggression, hyperactivity and social skills but viewing age-inappropriate content was linked with all the aforementioned negative effects (Conners-Burrow et al., 2011). Gentile et al. (2014) found that parental monitoring of young childrens media use had a protective effect on pro-social and aggressive behaviour. In the same study, it was also discovered that one of the mediators of the effect was viewing violent content.

In general, the literature on the social effects of media use is inconclusive. Research has pointed to other key variables such as type of content (Johnson, 2012) and type of media (ConnersBurrow et al., 2011) which may influence the relationship between media usage and social outcomes. Another factor which we may need to take into account is the Time Displacement Hypothesis advanced by Putnam (1995). Putnam posited that being highly engaged in television viewing robbed people of their time to participate in activities outside of the house. His framework has since been expanded to explain the relationship between media use and obesity (Buijzen et al., 2008; Burdette \& Whitaker, 2005) where high durations of media use displaces time for other physical activities and the lack of physical activity results in obesity. Similarly, Putnams theoretical construct could be applied to psychosocial adjustment variables. Therefore, we aim to explore and describe: 1) trends of media use in terms of type of gadgets, content and duration of use and 2) the relationship between duration of gadget use and psychosocial outcomes such as hyperactivity, peer relationship problems, emotional problems, conduct problems and prosocial behaviour.

\section{METHODOLOGY}

\section{Sample}

The respondents of this study are parents of 5 and 6 years old children from public and private kindergartens in Tanjong Malim. The parents were sampled using convenient sampling. A total of 40 questionnaires were distributed at both institutions to parents and 27 of the parents returned the completed questionnaire, a return rate of $67.5 \%$. The final sample of this study consist of only those children $(n=27)$ whose parents returned the questionnaire. The demographic information of the respondents is tabulated in Table 1. 
Table 1 Demographic Variables

\begin{tabular}{lcl}
\hline \multicolumn{2}{l}{ Demographic Variables Mother } & \multicolumn{1}{l}{ Father } \\
\hline $\begin{array}{l}\text { Race }(f, \%) \\
\text { - Malay }\end{array}$ & $26(96.3 \%)$ & $26(96.3 \%)$ \\
$\begin{array}{l}\text { Occupation }(f, \%) \\
\text { - Public Servant }\end{array}$ & $22(81.5 \%)$ & $10(37 \%)$ \\
- Private Sector & $2(7.4 \%)$ & $9(33.3 \%)$ \\
- Housewife & $2(7.4 \%)$ & $7(25.9 \%)$ \\
Age $(M, S D)$ & $35.58(4.45)$ & $36.42(4.58)$ \\
Income $(M, S D)$ & $4073.08(2128.39) 3638.46(2421.91)$
\end{tabular}

\section{Instruments}

The instruments used in this study are the Gadget Use Survey and the Strength and Difficulties Questionnaire. The Gadget Use Survey is adapted and translated to Malay from Kabali et al. (2015) which measures a few media related variables such as duration of use. The modified version of the questionnaire contains 17 items which assessed gadget use, specifically smartphones and tablets, such as what do children use the gadgets for, when did they first use the gadgets and the favourite content of their children on these devices. The questionnaire contained items such as Please $\checkmark$ the following activities which your child has used a gadget for. You may check more than one activity. Parents can select a number of responses which included watching videos, playing games, listening to music and taking pictures. The questionnaire was answered by the parents to assess preschooler's gadget use habits at home.

The Strength and Difficulties Questionnaire was used to assess psychosocial adjustment in children which was rated by the parents. The questionnaire was developed by Goodman (1997) and is a widely used instrument which is available online at the following website http://www.sdqinfo.com/a0.html. The translated version of the questionnaire was available online which the authors of the questionnaire translated with the help of a native Malay speaker (Youth in Mind, n.d.). The 25 items in the questionnaire are divided equally among the 5 dimensions and are answered on a 3-point scale, Not True, Somewhat True and Certainly True. As for scoring items number 7, 11, 14, 21 and 25 are reverse scored and the items within each subscale are summed up to calculate the score of each dimension. The questionnaire assessed a single dimension of strength which is prosocial and 4 dimensions of difficulties which are peer relationship problems, hyperactivity, conduct problem and emotional problems. The SDQ results can be interpreted in several ways as a 2 -subscale measure comprising of Difficulty Score and Strength Score or as 5-subscale score made up of prosocial, peer relationship problems, hyperactivity, conduct problem and emotional problems. For the purposes of this study, the 5 subscale interpretation is used. Examples of items in the questionnaire are: Considerate of other people's feelings, Constantly fidgeting or squirming and easily distracted, concentration wanders. The questionnaire obtained acceptable internal consistency based on the sample of the study for both parent-rated $(\alpha=0.7)$. Overall the validity and reliability of the SDQ has been found in multiple languages such as Spanish (Blumert, 2012), German (Lohbeck et al., 2015), Dutch (Mieloo et al., 2012) and English Mieloo et al. (2012). This seem to suggest that the SDQ has a stable factor structure in regardless of the language of administration. 


\section{Statistical Analysis}

The statistical analysis was carried out using Statistical Package for Social Sciences (SPSS) version 23 and $\mathrm{R}$ software version 3.4.1 (R Core Team, 2017). The analysis of the trends was carried out using SPSS while R was used for the LOESS smoothing. The following packages in R was used ggplot2 (Wickham, 2009) and Rmisc (Hope, 2013).

\section{FINDINGS}

In this section, three key findings on the trends of media usage among pre-schoolers will be presented. They are the prevalence of devices at home, usage and ownership, favourite contents of pre-schoolers and adherence to AAP recommendations. Apart from the trends, the functional relationship between the duration of use and psychosocial adjustment variables is explored.

Firstly, with respect to the trends of media use it is evident in Figure 1 that the most prevalent mobile device at home is the smartphone $(96.3 \%)$ followed by laptop (92.6\%, desktop $(77.8 \%)$ and tablet (51.9\%). Correspondingly, the most used device is smartphone $(92.6 \%)$ followed by laptop $(70.4 \%)$, tablet $(59.3 \%)$ and desktop $(25.9 \%)$. The pattern suggests that availability of media devices at home is associated with usage among pre-schoolers. However, in terms of ownership, the most popular device is the tablet where approximately one-third of the respondents reported their children owned a tablet.

Secondly, with regards to favourite content, it was found that $50 \%$ of the responses were games followed by educational content (23.69\%) and cartoons (18.42\%). Contents classified as Music were the least favourite among pre-schoolers where merely, $2.63 \%$ of the responses by parents were classified into that category. See Figure 2 for an illustration of the results.

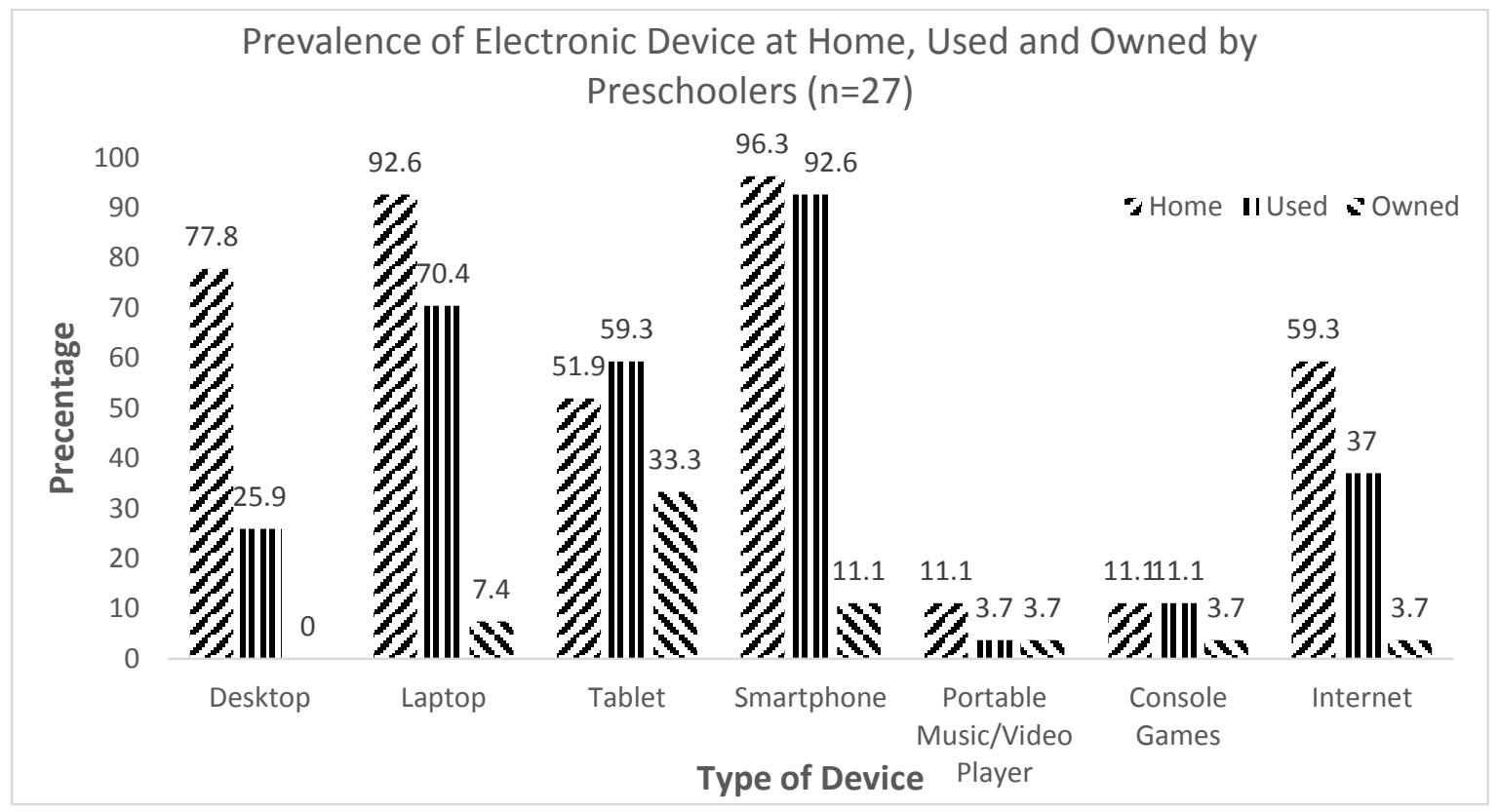

Figure 1. Prevalence of Device at Home, Used and Owned among Pre-schoolers. 


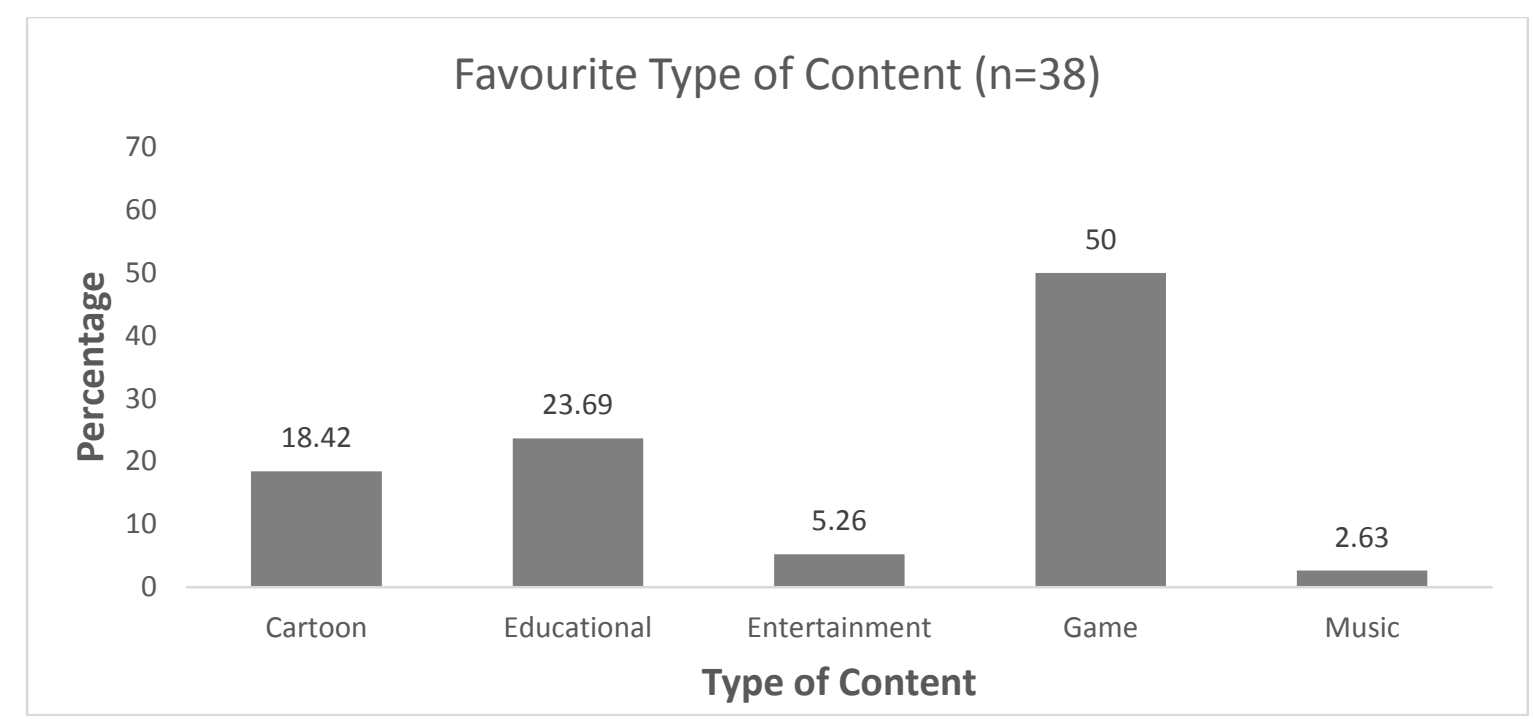

Figure 2. Favourite Type of Content.

The final trend examined in this study is adherence to AAP recommendations of no more than 2 hours of gadget use per day (AAP, 2016). It was found that more than $40 \%$ of the children involved in this study failed to adhere to AAP recommendations.

The results of the smoothing and linear graph for SDQ-Mal subscale scores and duration of use is available in Figure 3. It is clear that a greater proportion of the observations fall in the 95\% confidence interval for the LOESS smoothing curve compared to the linear line of best fit. The smoothed curve suggests that the relationship between Hyperactivity, Conduct Problems, Emotional Problems, Peer Relationship Issues and Prosocial Behaviour with duration of use is curvilinear in nature. Initially, both variables are positively related up to a threshold, about 100120 minutes, where the relationship becomes negative. A similar pattern of result is observed for the rest of the psychosocial issues variables with the exception of prosocial scores where the relationship is the exact opposite. Evidently, assuming a linear relationship between both variables is a serious oversimplification of the functional relationship. 

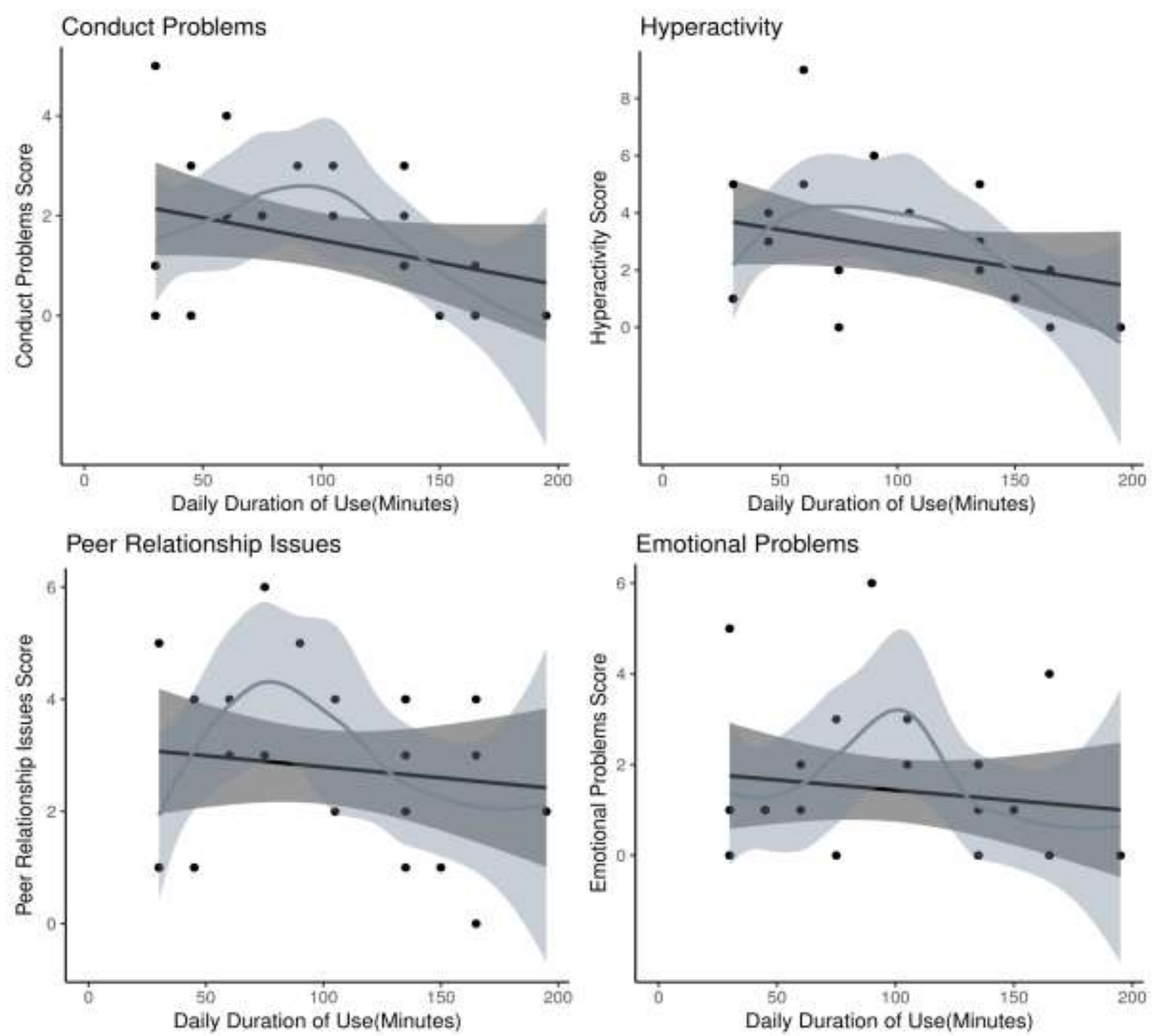

Prosocial Behaviour

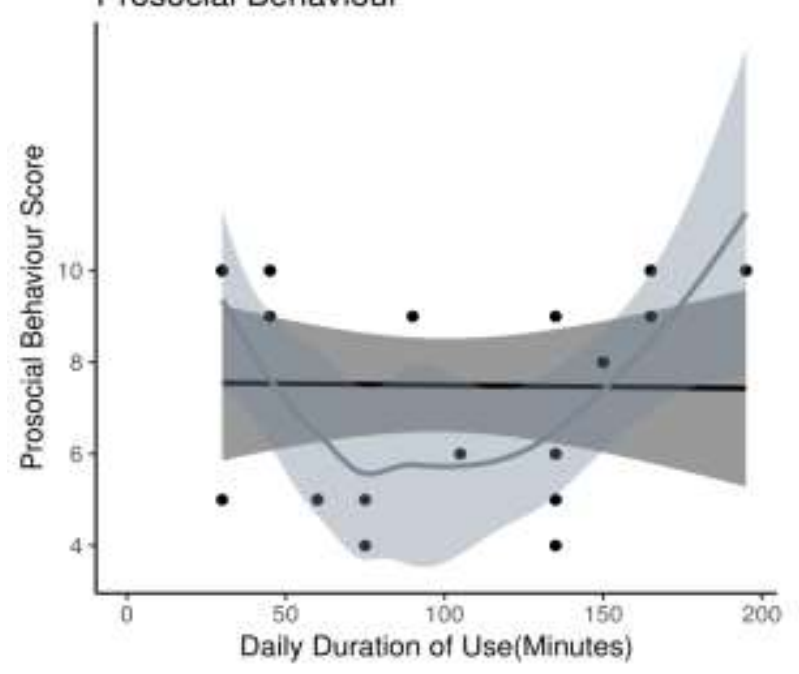

Legend

LOESS Smoothed Curve

Linear

Figure 3. LOESS Smoothing of Duration of Use and SDQ-Mal Subscale Scores. 


\section{DISCUSSION}

Media use in children has garnered considerable attention globally, however the same cannot be said in Malaysia despite the MCMC (September 29, 2017) reporting all time high broadband and mobile device penetration rates. In the present study it was found that smartphones are the most prevalent device at home and the most commonly used gadget among pre-schoolers which corroborates the findings of prior studies (Kabali et al., 2015; Dinleyici et al., 2016). This finding indicates a possible link between availability of gadgets at home and use of gadgets among children. Interestingly, while smartphones are the most prevalent and most used device, in terms of device ownership, three times as many parents elect to allow their children to own tablets compared to smartphones. The data implies a preference for tablet among parents and it is further substantiated by the fact that the proportion of 5 and 6 year olds who have used tablets is slightly higher when compared to availability of tablets at home, and note that tablets are the only device to display this pattern. On top of that, there are several appealing qualities of tablets such as the larger screen size and ease of handling. Another plausible explanation is that parents are using IPads as child minders to enable themselves to use their own devices or free themselves for other tasks. Regardless of the underlying rationale, there is a pressing need for larger scale studies to investigate this phenomenon.

In terms of content, about half of the parent reported favourite type of content were classified as games. The findings indicate that Malaysian pre-schoolers are largely using media devices for leisure purposes and these findings are in par with Kabali et al. (2015) who reported that content delivery applications and games are popular among young children. The appeal of these devices among children is understandable, these devices "respond" to touch by either lighting up or producing sounds which attracts children. Additionally, it should not be overlooked that these devices offer a plethora of options and each child can pick and choose the video or game of their liking as opposed to traditional media devices such as the television where children are merely passive consumers. Given that pre-schoolers have a proclivity for games on mobile devices and the autonomy to pick any number of games offered, a major concern is whether the content in the games are age appropriate. Gentile et al. (2014) have found that parental monitoring had a protective effect on young children's pro-social and aggressive behaviour and the relationship is mediated by consumption of age inappropriate content which in their case was violent content. It is undeniable that games and, by extension, mobile devices are increasing in popularity among children and it is fundamental that parents monitor and manage their child's usage.

An unexpected finding was that more than $40 \%$ of the children failed to adhere to AAP recommendations of no more than 2 hours of combined media usage per day. This is an alarming trend as a number of studies have associated media use with adverse psychosocial outcomes (Fitzpatrick et al., 2012; Gentile et al., 2014; Johnson, 2012). A possible explanation for this maybe that longer durations of media usage robs children of the precious parent-child interaction which is needed for healthy psychosocial development in children. This is in line with the Time Displacement Hypothesis as posited by Putnam (1995) which was previously used to account for the relationship between duration of media use and obesity in children.

The functional relationship between duration of gadget use and psychosocial adjustment appears to be non-linear. The smoothed curve shows that the relationship between psychosocial variables and duration of gadget use is curvilinear. There are a greater number of observations falling in the $95 \%$ confidence interval width of the smoothed curve compared to the linear line of best fit. This is an indication that the LOESS smoothed curve is a much better fit for the 
present data and is consistent with claims made by Keele (2008) that data in social psychology is rarely linear. Therefore, running conventional linear regression analysis for the data might result in biased estimates and it would be wise to heed the advise of Keele (2008) to analyse the data using semiparametric regression.

The findings of our study seem to be consistent with Putnam's hypothesis where durations of use greater than the 100 to 120-minute mark showed a decline in psychosocial issues and prosocial behaviour as reported by parents. While two hours, which is incidentally the suggested duration of use by the AAP, out of 24 hours may appear to be a small part of the child's life, in reality it takes up a considerable amount of time. A child in an average family with both parents working office hours has a mere three to four hours of time at home with their parents. A 100 to 120 minutes of device use is equivalent to half of that time and taken into account the time for dinner, personal hygiene and household chores, we realise that there is not much time left for parent-child interaction. The lack of parent-child interaction and the fact that children who are engaged in media use are sedentary most of the time may account for the decreased parent reported psychosocial issues and prosocial behaviour.

A major strength of the current study is that it is one of the first to investigate the trends of media use and psychosocial adjustment among 5 and 6-year-old pre-schoolers from a Malaysian perspective. While the current study does reveal several interesting finds, there is however a caveat that the data is from a small scale pilot study, with a sample size of $n=27$. Once again, larger scale studies are needed to further substantiate the findings in the current study, focusing on two fundamental variables of media use which are content and duration of use.

\section{FUNDING}

This study was funded by the National Child Development Research Centre (grant code: 20170007-106-04).

\section{REFERENCES}

AAP. (1999). Media education. Pediatrics, 104 (2), 341-343.

AAP. (2011). Media use by children younger than 2 years. Pediatrics, 128 (5), 1040-1045. doi: 10.1542/peds.2011-1753

AAP. (2016). Media and young minds. Pediatrics. doi: 10.1542/peds.2016-2591

Apple. (September 29, 2017). Apple-education-ipad-apps, books and more. Retrieved from https:// www.apple.com/education/apps-books-and-more/

Australian Department of Health. (15 June, 2017). National physical activity recommendations for children $0-5$ years. Retrieved from http://www.health.gov.au/internet/ main/publishing.nsf/content/F01F92328EDADA5BCA257BF0001E720D/\$FileMovel\%20and1\%20playl $\% 20$ every\\%20day $\% 200-5 y r s . P D F$

Blumert, H. M. (2012). Psychometrics of the SDQ in Spanish (Unpublished doctoral dissertation). Rutgers University.

Buijzen, M., Bomhof, E., \& Schuurman, J. (2008). A test of three alternative hypotheses explaining the link between children's television viewing and weight status. Journal of Children and Media, 2 (1), 67-74.

Burdette, H. L., \& Whitaker, R. C. (2005). A national study of neighborhood safety, outdoor play, television viewing, and obesity in preschool children. Pediatrics, 116 (3), 657-662.

Canadian Society for Exercise Physiology. (15 June, 2017). Canadian sedentary behaviour guide- lines. Retrieved from http://www.csep.ca/CMFiles/Guidelines/CSEP SBGuidelines early-years en.pdf

Conners-Burrow, N. A., McKelvey, L. M., \& Fussell, J. J. (2011). Social outcomes associated with media viewing habits of low-income preschool children. Early Education and Development, 22 (2), 256-273. 
Dinleyici, M., Carman, K. B., Ozturk, E., \& Sahin-Dagli, F. (2016). Media use by children, and parents views on children's media usage. Interactive journal of medical research, 5 (2).

Fitzpatrick, C., Barnett, T., \& Pagani, L. S. (2012). Early exposure to media violence and later child adjustment. Journal of Developmental \& Behavioral Pediatrics, 33 (4), 291-297.

Game Industry Promotion Act. (2015).

Gentile, D. A., Reimer, R. A., Nathanson, A. I., Walsh, D. A., \& Eisenmann, J. C. (2014). Protective effects of parental monitoring of childrens media use: a prospective study. JAMA Pediatrics, 168 (5), 479-484.

Goodman, R. (1997). The strengths and difficulties questionnaire: a research note. Journal of Child Psychology and Psychiatry, 38 (5), 581-586.

Hope, R. M. (2013). Rmisc: Ryan Miscellaneous [Computer software manual]. Retrieved from https://CRAN.Rproject.org/package $=$ Rmisc $(\mathrm{R}$ package version 1.50).

Johnson, G. (2012). Learning, development, and home digital media use among 6 to 8 year old children. Problems of Psychology in the 21st Century, 1, 6-16.

Kabali, H. K., Irigoyen, M. M., Nunez-Davis, R., Budacki, J. G., Mohanty, S. H., Leister, K. P., \& Bonner, R. L. (2015). Exposure and use of mobile media devices by young children. Pediatrics, 136, 1044-1050. doi: 10.1542/peds.2015-2151

Keele, L. J. (2008). Semiparametric regression for the social sciences. John Wiley \& Sons.

Lohbeck, A., Schultheiss, J., Petermann, F., \& Petermann, U. (2015). The german self-report version of the strengths and difficulties questionnaire (sdq-deu-s): Psychometric properties, factor structure, and critical values. DIAGNOSTICA, 61 (4), 222-235.

MCMC. (September 29, 2017). Communications multimedia: Facts figures. Retrieved from https://www.mcmc.gov.my/skmmgovmy/media/General/pdf/1Q17-facts-figures.pdf

Mieloo, C., Raat, H., van Oort, F., Bevaart, F., Vogel, I., Donker, M., \& Jansen, W. (2012). Validity and reliability of the strengths and difficulties questionnaire in 5-6 year olds: differences by gender or by parental education? PloS one, 7 (5), e36805.

Pew Research Centre. (November 10, 2015). Apps permissions in the Google Play Store. Retrieved from https://www.pewinternet.org/2015/11/10/an-analysis-of-apps-in-the-google-play-store/

Protection of Children \& Youths Welfare \& Rights Act. (2017).

Putnam, R. D. (1995). Bowling alone: America's declining social capital. Journal of Democracy, 6 (1), 65-78.

Radesky, J. S., Schumacher, J., \& Zuckerman, B. (2015). Mobile and interactive media use by young children: The good, the bad, and the unknown. Pediatrics, 135 (1), 1-3. doi: 10.1542/ peds.2014-2251

R Core Team. (2017). R: A language and environment for statistical computing. [Computer software manual]. Vienna, Austria. Retrieved from https://www.R-project.org/

Wickham, H. (2009). ggplot2: Elegant graphics for data analysis. New York, NY: Springer-Verlag.

Youth in Mind. (n.d.). Strengths and Difficulties Questionnaire. Retrieved from http:// www.sdqinfo.com/d0.html 